\title{
The term structure, leading indicators, and recessions: evidence from Switzerland, 1974-2017
}

Rebecca StuartiD

\begin{abstract}
This paper studies the predictive power for recessions of the slope of the Swiss term structure using monthly data for 1974-2017. Dynamic probit models indicate that the term structure contains information useful for predicting recessions for horizons up to 19 months. Whether the economy is currently in recession or not is also useful for forecasting recessions. These relationships prove stable over the sample. Robustness tests indicate that the KOF business course indicator and some monetary aggregates contain different information from the term structure which can improve the in- and out-of-sample fit of the model.
\end{abstract}

Keywords: Switzerland, Term structure, Recessions, Leading indicators

JEL: C25, E00, E43

\section{Introduction}

This paper studies the ability of the slope of the term structure of interest rates to predict recessions in Switzerland using monthly data over the period 1974 to 2017. It is particularly interesting to study this relationship because Switzerland has experienced a number of external shocks since the collapse of the Bretton Woods system in $1974 .^{1}$ Nonetheless, the power of the term structure in predicting Swiss recessions has apparently not previously been studied in the literature. ${ }^{2}$

\footnotetext{
${ }^{1}$ Many of these shocks were related to sharp exchange rate movements arising from the Swiss franc's traditional role as a safe haven currency. Relatedly, the Swiss National Bank (SNB) has changed the weight it attaches to the exchange rate in setting monetary policy over time, most recently by adopting an exchange rate floor of 1.20 Swiss Francs per euro between 2011 and 2015. For a discussion of Swiss monetary policy see, for instance, Baltensperger and Kugler (2016).

${ }^{2}$ The closest paper to the current study is that of Gerlach-Kristen (2007), which considers the predictive power of the term structure for inflation and unemployment over the period 1989-2005 and finds that it has predictive power for unemployment but not inflation, and only in the period before the introduction of inflation targeting by the SNB in 2000. Swiss data are also included in the multi-country studies of the predictive power of the term for inflation and interest rates of Jorion and Mishkin (1991) and Mishkin (1991).
}

Correspondence: rebecca.j.stuart@gmail.com; http://rebeccastuart.net Central Bank of Ireland, New Wapping Street, North Wall Quay, Dublin 1, Ireland
In contrast, the literature for the United States of America (US) is extensive. An early study of the predictive power of the US term structure for economic activity was provided by Harvey (1989). In terms of its forecasting capacity for recessions, Estrella and Hardouvelis (1991) first demonstrated this using probit models. Since then, a wider literature has built up studying various aspects of this relationship. ${ }^{3}$

However, the predictive power of the slope of the term structure for recessions in other economies is less studied. Estrella and Mishkin (1995) find that the term structure predicts recessions reasonably well in the US and Germany, to a lesser extent in the UK and Italy, and hardly at all in France. Bernard and Gerlach (1996) show that the slope of the term structure of interest rates has, to varying extents, predictive power for recessions in Belgium, Canada, France, Germany, Japan, the Netherlands, the UK, and the US over the period 1972 to 1993. They also show that, although foreign spreads

\footnotetext{
${ }^{3}$ Most recently, Bauer and Mertens (2018) consider conditions in the post-Global Financial Crisis period have impacted the predictive power of the term spread, while Adrian, Estrella, and Shin (2018) propose a 'risk-taking channel' through which a yield curve inversion can impact the real economy via banks' net interest margins.
} 
may be statistically significant in explaining recessions, their economic importance is limited. ${ }^{4}$

There are two reasons why the slope of the term structure may be less informative in small and highly open economies than in larger and more closed economies. First, central banks in small open economies tend to fix, or manage heavily, their exchange rates. With interest rates consequently determined, or strongly influenced, by those abroad, the domestic term structure may reflect only to a limited extent domestic economic conditions. Furthermore, even if the exchange rate floats, economic and financial developments in large neighbors and important trading partners can impact on the domestic term structure, potentially swamping the information it contains about the national economy.

Second, economic conditions in many small open economies are often disproportionally dependent on the fortunes of a small number of large companies that are heavily engaged in international trade. Sudden developments impacting on these companies can have an outsize impact which can lead to particularly large revisions in macroeconomic data. ${ }^{5}$

Overall, therefore, it is an open question whether the slope of the term structure is useful in predicting recessions in small open economies. In this paper, I address this question using dynamic probit models to forecast recessions in Switzerland over the period 1974-2017. The monthly data set comprises the 3-month interbank rate, 10-year Government bond yields, and the recession dating of the Organisation for Economic Co-operation and Development (OECD). ${ }^{6}$ Using the latter rather than gross domestic product (GDP) growth has two main advantages. First, the data are available monthly, whereas the highest frequency that GDP is available is quarterly. While monthly data are likely to be noisier than quarterly data, the number of observations triples. This is likely to lead to better (and, in any case, timelier) estimates. Second, consistent official quarterly GDP data for Switzerland begin only in $1980 .^{7}$ Dropping the 1970s seems unfortunate, since it is a period that is likely to be highly informative about the ability of the term structure to predict recessions.

The main findings are as follows. First, there is considerable evidence that the slope of the Swiss term structure contains information useful for forecasting

\footnotetext{
${ }^{4}$ Another study of European data, this time by Moneta (2005) on euro area data, finds that the spread between the 10-year and 3-month rate is the best predictor of recessions, and that this model performs best at the 1-year horizon.

${ }^{5}$ The macroeconomic consequences for Finland of the collapse of Nokia, and for Ireland of movements in the balance sheet of Apple, are cases in point. See Forbes (2016).

${ }^{6}$ All data are sourced from the Federal Reserve Bank of St Louis' FRED database.

${ }^{7}$ See Stuart (2018) for a discussion.
}

recessions for horizons up to 19 months ahead in the sample period studied. This result compares well with those in the literature for small open economies. Indeed, a comparison with a similar specification for the US-a large, relatively closed economy-suggests that the insample fit of the models is surprisingly similar, although the US model has a better out-of-sample fit. Second, whether the economy is currently in recession or not is also useful information. For short forecast horizons, the results indicate that the economy is expected to stay in its current state; for longer forecast horizons, the results show that the economy is likely to change state. Third, these relationships appear stable over time. Fourth, robustness tests indicate that the KOF Swiss Economic Institute (KOF) business course indicator and M1 and M2 growth contain information not already embedded in the term structure. Combining the term structure and these additional variables improves the overall in-sample fit of the model. Out-of-sample testing suggests that the KOF indicator, in combination with M1 or M2 growth, improves the overall fit of the model at most horizons.

The paper is structured as follows. The data and some historical background are discussed in the next section. Section 3 presents the results of the model, including analysis of parameter stability and fit. In Section 4, a number of robustness tests are carried out to consider the information content of alternative measures of the spread, and additional variables. Section 5 compares the relationship between recessions and the term spread in Switzerland with that in the US, on which much of the literature has focused. Section 6 concludes.

\section{Data and a brief historical background}

I use monthly data on 10-year government bond yields, 3-month interbank rates, and recessions as captured by the OECD's recession dating for Switzerland. The interbank rate is used as it is available since 1974. An alternative is the 3-month Swiss LIBOR rate, which was the operational target of the SNB between 2000 and 2019. ${ }^{8}$ However, this series is only available since the beginning of 1989. Nonetheless, the two rates are very similar: their correlation is over 0.99 for the period since January 1989. ${ }^{9}$

The recession indicator is a dummy variable that takes a value of one from the period after a peak in the business cycle through to the trough. The turning points in the business cycle are measured using the OECD's composite leading indicator (CLI), which is calculated using

\footnotetext{
${ }^{8}$ In January 2000, the SNB adopted a new monetary policy regime which set out a target for consumer price inflation of "less than 2 per cent", and was implemented through a target range for 3-month Libor. ${ }^{9}$ Another short interest rate that is available on a monthly frequency since 1974 is the call money rate. The main findings are unchanged if this rate is used instead of the 3 -month interbank rate.
} 


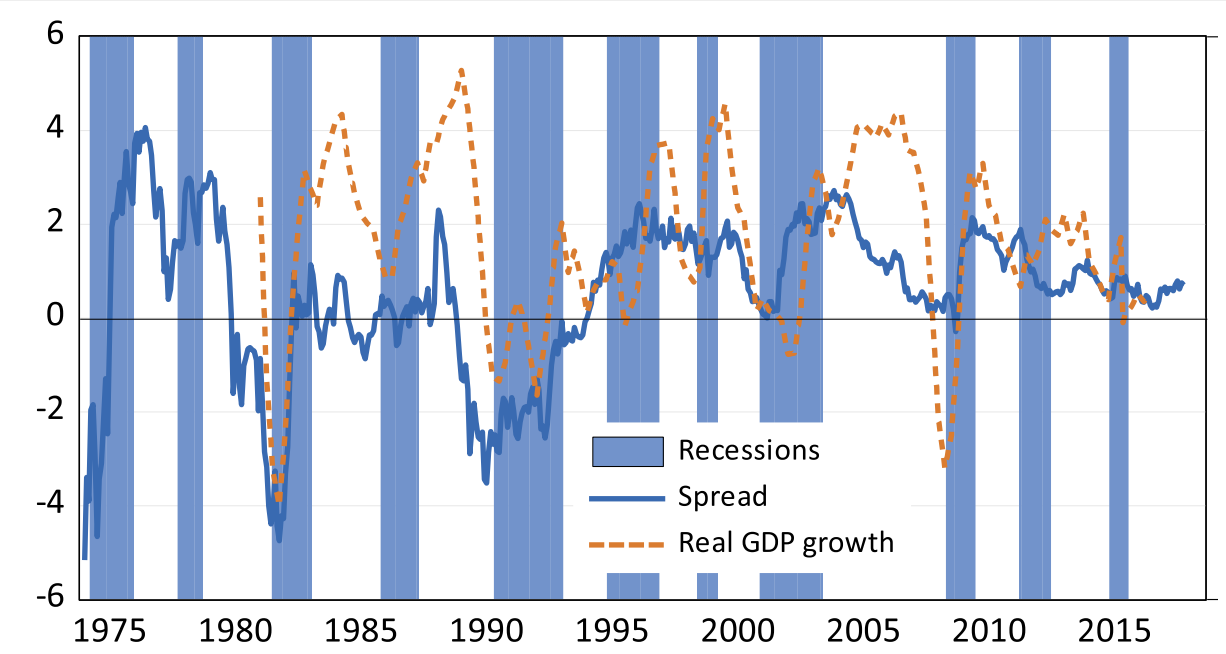

Fig. 1 Recessions, term spread and real GDP growth, 1974-2017

six monthly series capturing manufacturing activity, consumer sentiment, and financial markets. ${ }^{10}$ To my knowledge, this is the only indicator of recessions available on a monthly frequency over this sample period.

Figure 1 shows the recession dummy and the quarteron-quarter real GDP growth over four quarters, which is available since 1980. Since the recession indicator takes a value of one in the period after a peak in the cycle, it tends to signal recessions before real GDP growth turns negative. Interestingly, the indicator suggests that the Swiss economy was in recession in 2015 following the removal of the exchange rate floor with the euro. In contrast, few commentators consider the Swiss economy to have been in recession then since GDP growth was negative for just one quarter.

However, in general, the two measures coincide well. ${ }^{11}$ Overall, it is clear from Fig. 1 that quarter-on-quarter real GDP growth is generally much lower in recessions, during which quarter-on-quarter growth averages approximately $-0.04 \%$, than in expansions, when quarteron-quarter growth averages approximately $0.72 \%$.

\footnotetext{
${ }^{10}$ Specifically, the CLI for Switzerland is computed using: three manufacturing series (finished goods stocks: level (compared to previous month, \% balance) inverted, orders inflow: tendency seasonally adjusted (compared to previous month, \% balance), production: future tendency seasonally adjusted (next three months, \% balance), one financial series: (share prices: UBS-100 index (2015 = 100)), one consumer sentiment series (expected economic situation seasonally adjusted (\% balance)), and silver prices (CHF/kJ). See: http:// www.oecd.org/sdd/leading-indicators/CLI-components-and-turningpoints.pdf and metadata for the individual series in the Business Tendency Surveys section of the OECD online database: https://stats.oecd. org/Index.aspx?DataSetCode=MEI_BTS_COS.

${ }^{11}$ There is only one instance, in 1994, when quarterly GDP growth turned negative, but the recession indicator does not signal a recession. However, in this case, GDP growth was only negative for one quarter.
}

Figure 1 also includes the spread between the 10-year government bond yield and the 3-month interest rate. The literature suggests that when the term structure is inverted, that is, when the short rate is higher than the long rate, a recession is more likely. From Fig. 1, the term spread is clearly inverted prior to a number of recessions in 1970s, 1980s, and early 1990s. However, although it narrows, it does not become inverted in advance of the other recessions in the sample.

To consider the evolution of the Swiss term spread and recessions in more detail, note that when the sample begins in 1974, the term structure is already inverted, and the first recession occurs almost immediately thereafter. At that time, the Swiss Franc had just been floated following the collapse of the Bretton Woods system. ${ }^{12}$ It is interesting that the largest inversions of the term spread (up to $4 \%$ ) occur in the early part of the sample when the Swiss Franc was first floating and the SNB started to conduct independent monetary policy. These inversions coincide with some of the deeper declines in real GDP growth occurred at these times.

In response to this sudden lack of an exchange rate anchor, the SNB adopted a policy of targeting M1 growth. The SNB's actions succeeded in slowing inflation, but also led to an abrupt reversal of the business cycle, as is evident from Fig. $1 .^{13}$ As a result, GDP declined markedly, and the economy entered a recession (Baltensperger and Kugler (2016), p. 70).

\footnotetext{
${ }^{12}$ Following the US decision to suspend convertibility, international market turbulence resulted in Switzerland attracting strong capital inflows, causing the SNB to float the Swiss Franc in 1973. The financial turmoil had resulted in the Swiss Franc being revalued prior to its floating (Marsten (1993)).

${ }^{13}$ Although using monetary targets from 1974, the SNB only publicly announced a target in 1975. See Baltensperger and Kugler (2016).
} 
While the economy emerged from that recession in late 1975, the SNB's success in reducing inflation came with the cost of strong capital inflows and a sharp appreciation of the Swiss franc. ${ }^{14}$ Industry came under increasing pressure with reports that "entire production facilities [had been abandoned] because of the exchange rate" (Bernholz (2007), p. 179). The result was that the spread was compressed and the economy moved into recession again in late-1977 (Fig. 1). To mitigate the impact of the exchange rate on economic activity, the SNB temporarily fixed the Swiss Franc vis-à-vis the German Mark in October 1978. ${ }^{15}$

Following a spike in inflation in the early 1980s after the re-floating of the Franc, the term spread inverted again, and the economy moved into recession in 1981. Thereafter, inflation declined through much of the mid1980s, and economic growth was low. Figure 1 shows that the spread was marginally inverted a number of times in advance of the economy slipping into recession in late-1985. A wider global slowdown, accentuated by the US stock market crash of October 1987, raised fears of a global slump, leading the SNB to maintain a more expansionary policy than otherwise. As a result, there was an upswing in the business cycle in 1987 (Fig. 1). ${ }^{16}$

Entering the 1990s, Switzerland experienced a sharp decline in house prices, while the economy was also buffeted by external shocks, including the fallout from the reunification of Germany and severe tensions in the European Monetary System (EMS). Overall, GDP growth slowed substantially, the spread became inverted again, and the economy slipped into recession through much of the early-1990s (Fig. 1). ${ }^{17}$

This recession was the last time that the long rate fell significantly below the short rate: since the mid-1990s, the term spread has narrowed but not turned negative in advance of recessions. For instance, following the failure of Lehman Brothers in September 2008, the downturn in the global economy, and in the euro area in particular, increasingly came to affect the Swiss economy, leading the SNB to introduce a number of measures including an exchange rate floor of Swiss Francs against the euro. Over the 10 years during which these events took place,

\footnotetext{
${ }^{14}$ Nelson (2007, p. 718) reports a senior SNB official as stating that adoption of monetary targets showed that 'we mean business'. Furthermore, the SNB's ability to regain control over inflation is impressive, particularly compared to other small open economies (Nelson (2007)).

${ }^{15}$ See Gerlach and Jordan (2012) for a discussion.

${ }^{16}$ It has been argued that this increase in inflation in the very early 1980s occurred because the SNB was too slow in removing the excess liquidity resulting from defending the currency during the period of exchange rate fixity. See Kugler and Rich (2002) and Rich (2003).

${ }^{17}$ See Kleinewefers Lehner (2007) for a discussion. While this was initially attributed to cyclical factors, it gave way to a prolonged period of lower growth.
}

although the term spread narrowed significantly in advance of recessions, only once during the recession in 2008 did it became negative.

\section{Estimation}

\subsection{Preliminary estimates}

To consider more formally the relationship between the term spread and recessions, I next present preliminary estimates using a probit model for the period January 1974 to October 2017.

As discussed in Kauppi and Saikkonen (2008), there are two possible ways to construct multi-period forecasts using such models. The first is the "direct" method, in which the recession indictor several months ahead is regressed on its current value and lagged values of the explanatory variables. The second is the "iterated" method, in which a one-period ahead forecast model is estimated and forecasts are computed iteratively for the desired forecast horizon. Since Kauppi and Saikkonen (2008) note that the ranking in efficiency of the two methods is theoretically ambiguous, and since the former is more common in the literature, ${ }^{18}$ this is the method used below. Therefore, the dependent variable is the recession dummy $h$ months ahead. In this subsection, I first set $h$ to 6 (months) to explore the nature of the relationship between the term structure and recessions in detail; below, I vary $h$ from 1 to 24 .

The first column of Table 1 presents the results, with conventional $\mathrm{t}$-statistics in parenthesis. The parameter on the spread is negative and significant, demonstrating that there is an inverse relationship between the spread and the likelihood of a recession in 6 months' time. Thus, as the spread narrows, the probability of being in recession in 6 months' time increases.

However, as is well known, conventional t-statistics are biased in this case since the forecast errors are overlapping (see Estrella (Estrella \& Mishkin, 1995)). Therefore, column 2 presents t-statistics computed assuming standard errors with a $(h-1)$ moving average. These are about half as large as conventional t-statistics, but the spread remains highly significant. In what follows, I therefore only use standard errors robust to serial correlation.

In addition, the recession dummy has its own autocorrelation structure, which may impact the predicted probabilities from these models. Furthermore, univariate time series modeling of macroeconomic data has demonstrated the importance of a variable's own history in generating forecasts. Thus, I next estimate a dynamic probit model ${ }^{19}$, as proposed by Dueker (1997), in which

\footnotetext{
${ }^{18}$ See Estrella and Hardouvelis (1991), Estrella and Mishkin (1995), Bernard and Gerlach (1996) among others.

${ }^{19}$ Similar models are considered by Moneta (2005), Gerlach and Stuart (2018), and Kauppi and Saikkonen (2008).
} 
Table 1 Probit model results, 6-month ahead forecast horizon, 1972M1-2017M10

\begin{tabular}{|c|c|c|c|c|c|c|c|c|}
\hline & (1) & (2) & (3) & (4) & $\begin{array}{l}\text { (5) Dummy = } 1 \\
\text { after } 1995 \mathrm{M} 8\end{array}$ & $\begin{array}{l}\text { (6) Dummy = } 1 \\
\text { after 2000M1 }\end{array}$ & $\begin{array}{l}\text { (7) Dummy = } 1 \\
\text { after 2007M1 }\end{array}$ & $\begin{array}{l}\text { (8) Dummy }=1 \\
\text { after } 2011 \mathrm{M} 9\end{array}$ \\
\hline Spread & $\begin{array}{l}-0.262^{* * *} \\
(6.758)\end{array}$ & $\begin{array}{l}-0.262^{* * *} \\
(3.621)\end{array}$ & $\begin{array}{l}-0.289^{* * *} \\
(4.095)\end{array}$ & $\begin{array}{l}-0.276^{* * *} \\
(3.867)\end{array}$ & $\begin{array}{l}-0.2941^{* * *} \\
(3.414)\end{array}$ & $-0.264^{* * *}(3.378)$ & $-0.286^{* * *}(3.900)$ & $-0.278^{* * *}(3.876)$ \\
\hline Recession & & & $\begin{array}{l}1.354^{* * *} \\
(5.848)\end{array}$ & & & & & \\
\hline $\begin{array}{l}\text { Recession } \\
\text { (third lag) }\end{array}$ & & & & $\begin{array}{l}0.658^{* * *} \\
(2.741)\end{array}$ & $0.783^{* *}(2.361)$ & $0.638^{*}(2.118)$ & $839^{* * *}(3.030)$ & $0.716^{* * *}(2.835)$ \\
\hline Dummy & & & & & $0.226(0.515)$ & $0.155(0.354)$ & $0.066(0.126)$ & $-0.674(0.658)$ \\
\hline $\begin{array}{l}\text { Dummy * } \\
\text { Spread }\end{array}$ & & & & & $0.005(0.017)$ & $0.159(0.520)$ & $0.165(0.337)$ & $0.538(0.466)$ \\
\hline $\begin{array}{l}\text { Dummy * } \\
\text { Recession }\end{array}$ & & & & & $-0.244(0.515)$ & $0.071(0.142)$ & $-0.894(1.627)$ & $-0.790(1.115)$ \\
\hline Constant & $\begin{array}{l}-0.138^{* *} \\
(2.244)\end{array}$ & $\begin{array}{l}-0.138 \\
(1.065)\end{array}$ & $\begin{array}{l}-0.699^{* * *} \\
(4.188)\end{array}$ & $\begin{array}{l}-0.398^{* * *} \\
(2.404)\end{array}$ & $-0.506^{*}(2.043)$ & $-408(1.841)$ & $-0.453^{* *}(2.313)$ & $-0.351^{* * *}(1.966)$ \\
\hline $\begin{array}{l}\text { Pseudo r- } \\
\text { squared }\end{array}$ & 0.096 & 0.096 & 0.315 & 0.144 & 0.147 & 0.146 & 0.173 & 0.182 \\
\hline
\end{tabular}

the autocorrelation in the recession indicator is dealt with by conditioning explicitly on its recent history. ${ }^{20}$

From column 3, the parameter on the recession dummy is highly significant and positive, indicating that if the economy is in recession today, it is likely to be so also in 6 months' time. This model is useful in understanding the historical evolution of the term spread and recessions in Switzerland over the sample period.

However, policymakers attempting to forecast recessions can only use the data available to them in real time. Since short interest rates are determined by policy, it is important that the information included in the prediction equation reflects the information available to policymakers. Referring to the US, Dueker (1997) argues that 3 months is the minimum reasonable "recognition lag" for policymakers to be sure that the economy is in a recession and I follow that convention here.

Thus, in column 4, the third lag of the recession dummy is included. The coefficient is highly significant. Since I am interested in whether the slope of term structure can be used as a real-time indicator of the likelihood of a recession, in the rest of the analysis I use the third lag of the recession dummy. This leads to fall in the pseudo $\mathrm{r}$-squared from 0.31 to 0.14 . Nevertheless, the results are fully supportive of the

\footnotetext{
${ }^{20}$ Kauppi and Saikkonen (2008) also propose an autoregressive probit model where the lagged value of the estimated probability of a recession is included as an explanatory variable. However, the authors find that there is little or no improvement in the inand out-of-sample fit of their models from arising from this specification, Thus, since it is also computationally onerous, it is not considered here.
}

view that the slope of the term structure predicts future recessions.

\subsection{Stability}

It seems plausible that over the 43-year sample period, which is marked by a series of large shocks, the relationship between the variables may change. Therefore, I next explore the stability of the relationship. In the absence of any prior knowledge of a specific break point, I first focus on the possibility of a break at the middle of the sample, since that maximizes the power of the test. To do so, I use a dummy variable that takes a value of one after August 1995. This dummy is included on its own in the probit model and is also interacted with the other explanatory variables.

The results are presented in column 5 of Table 1 . Neither the interaction terms nor the dummy itself are individually significant. A Wald test of their joint significance fails to reject the null ( $p$ value $=0.94$ ).

It is possible that a break occurred at a specific point in time when there was a shift in policy or a large shock. I next include a dummy that equals one after the SNB introduced its new monetary policy framework in 2000, as well as interaction terms. The results are shown in column 6 of Table 1. Again, the dummy and interaction terms are individually insignificant, while a Wald test for joint significance also fails to reject the null ( $p$ value $=$ 0.96). Similar results are found when dummies which take the value of one after the onset of the Great Financial Crisis in 2007 and after the SNB instituted the exchange rate floor in September 2011 are included (columns 7 and 8). Here, the power of the test is lower, since there are few non-overlapping periods for which 
the dummy takes a value of one. ${ }^{21}$ Perhaps not surprisingly, the Wald tests fail to reject the null hypotheses ( $p$ values of 0.42 and 0.16 , respectively).

Overall, it appears that the relationship between the variables is stable over the entire sample period.

\subsection{Results for horizons of $\mathbf{1}$ to $\mathbf{2 4}$ months}

So far, the analysis has considered the predictive power of the term spread for recessions at a 6 month horizon. Next, I generalize these results by letting the forecast horizon, $h$, vary from 1 to 24 . The point estimates for the coefficients on the spread, the recession dummy and the constant, along with two standard error bands, are presented in panels (a), (b), and (c) of Fig. 2. Consider panel (a): the horizontal axis indicates the forecast horizon at which the coefficient on the spread is estimated. For each horizon, the point estimate along with a plus/ minus two-standard error band is included in the figure. Panel (a) shows that the coefficient on the spread is significant up to $h=19$. Thus, it appears that the slope of the term structure has predictive power in excess of 18 months ahead.

These results are similar to those for some of the small open economies examined in the cross-country studies of Bernard and Gerlach (1998) and Estrella and Mishkin (1995). Bernard and Gerlach (1998) consider a comprehensive set of specifications over the period 1972 to 1993, estimating the predictive power of the spread for horizons of zero to eight quarters ahead. Here, I will focus on the results for four and six quarters ahead. They include the spread as the only explanatory variable in their baseline specification, which is estimated separately for eight countries: Belgium, Canada, France, Germany, Japan, Netherlands, the UK, and the US. ${ }^{22}$ They find that the spread is significant in probits forecasting Belgian, Canadian, French, German, UK, and US recessions four quarters ahead. ${ }^{23}$ It is insignificant in the probits for the Netherlands and Japan. Naturally, the longer the forecasting horizon, the lower the predictive power of variables. This is particularly the case for smaller, open economies: forecasting six quarters ahead, the spread is only significant for German and US recessions. Thus, although not directly comparable, the result that the Swiss term spread predicts recessions up to 19 months ahead, suggests that it has considerable

\footnotetext{
${ }^{21}$ For instance, there are 6 years (or 72 months) for which the dummy that takes a value of one after September 2011. However, since I am estimating 6-month ahead horizons, the number of non-overlapping periods is just 12 .

${ }^{22}$ Unfortunately, Bernard and Gerlach (1998) do not estimate a specification in which a current or lagged value of the recession indicator is included.

${ }^{23}$ See Bernard and Gerlach (1996), Table 1, results assuming MA errors of order $k-1$.
}

predictive power given that Switzerland is a small open economy.

Unfortunately, Bernard and Gerlach (1996) do not report coefficient estimates. In contrast, Estrella and Mishkin (1995) do. They estimate a probit model in which recessions four quarters ahead are determined by the spread and a leading indicator of the business cycle over the period 1973 to 1994 . They find that the spread is significant at the 5\% level in Germany, Italy, the UK, and the US, but not in France. ${ }^{24}$ Notably, the spread parameter is larger in Germany and the US (approximately 0.80 ), compared to the smaller, more open economies of the UK and Italy (approximately 0.30). Interestingly, the coefficient estimates for the Swiss term structure 12 months ahead are of a similar magnitude to those for the UK and Italy.

Turning to the estimated coefficients on the third lag of the recession dummy, panel (b) of Fig. 2 suggests that the current value of the recession dummy is significant and positive at short forecast horizons, indicating that if the economy is in recession now, it is more likely to be so in a few months' time. The significance declines as the forecast horizon increases: when forecasting 9 months ahead, the coefficient on the recession indicator is no longer significant. However, at longer horizons (for $h>14$ ), the coefficient is again significant, but it is now negative. Intuitively, this suggests that if the economy is currently in recession, it is likely to emerge from this after 15 months.

Next, I consider the importance of the term spread. Figure 3 shows the estimated probability of being in recession in 6 and 12 months' time as a function of the current spread, assuming that the economy is currently not in recession. The probabilities in the figure are calculated for values of the spread between -5 and $4 \%$, which is approximately the range observed in the sample period.

When the spread is $4 \%$, that is, the long rate is 4 percentage points above the short rate, the probability of being in a recession 6 months later is about 3\%. However, as the spread declines, the probability rises. When the long and short rates are equal so that the spread is zero, the probability of a recession in 6 months' time is approximately $25 \%$. Once the slope of the term structure is inverted, the probability of a recession in 6 months' time rises rapidly. When the short rate is 3 percentage points higher than the long rate, the probability of recession in 6 months' time is over $50 \%$. A similar pattern is evident at a 12-month horizon, although the probabilities are generally somewhat higher for each value of the spread.

\footnotetext{
${ }^{24}$ See Estrella and Mishkin (1995), Table 3.
} 


\section{(a) Spread, estimated coefficients}

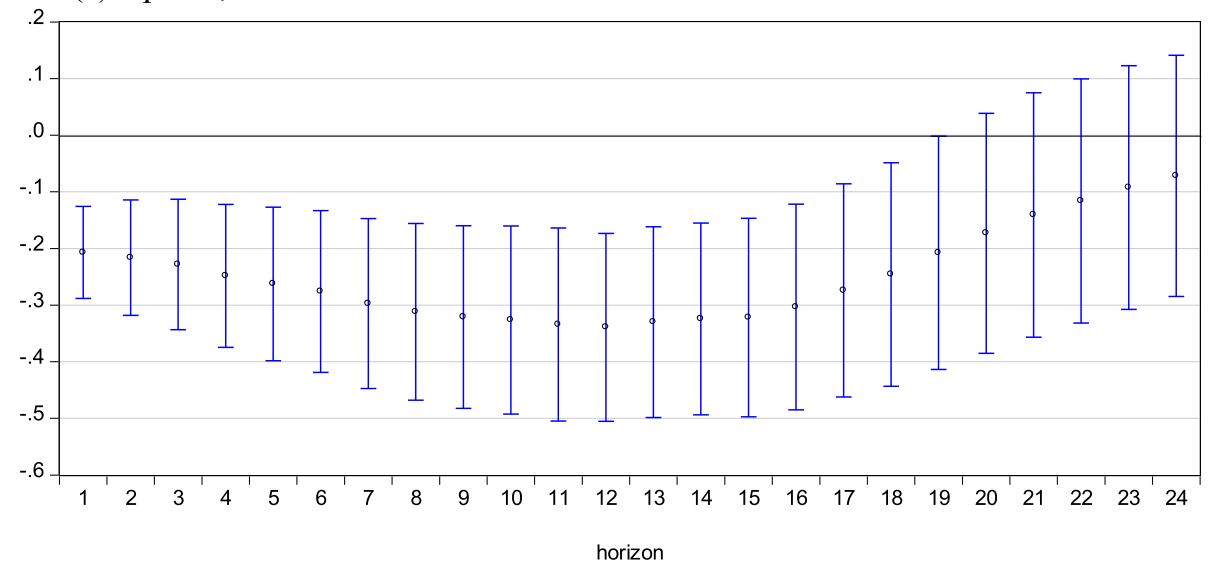

(b) Recession dummy, estimated coefficient

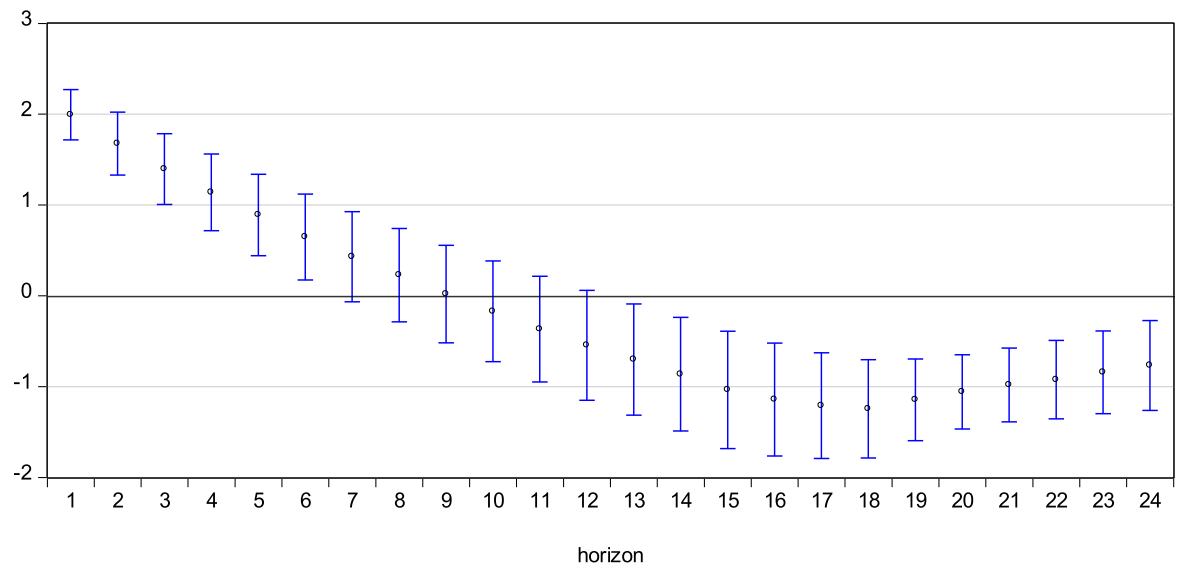

(c) Constant

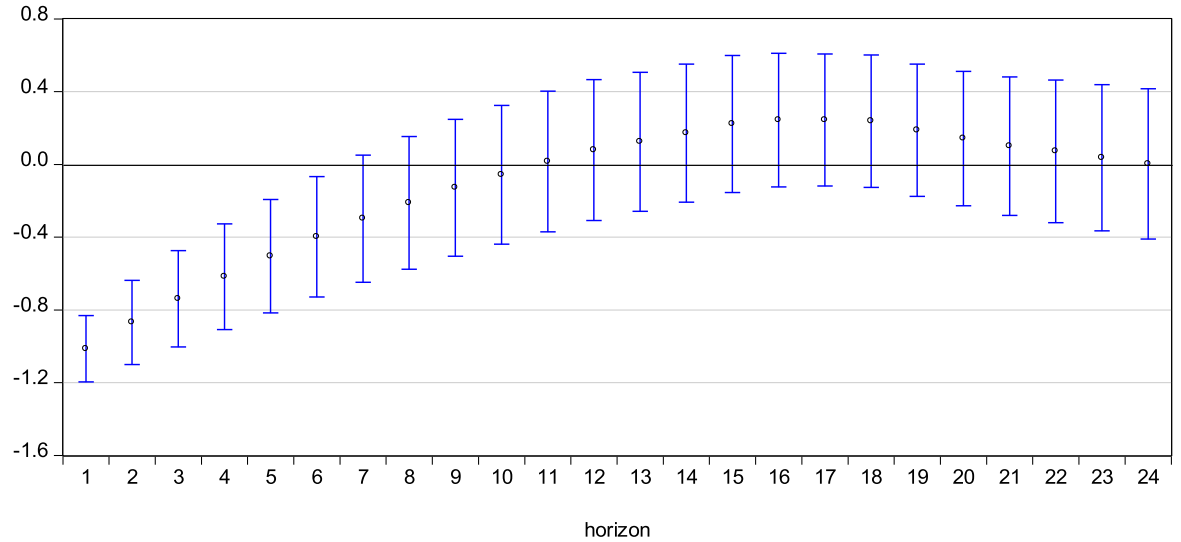

Note: Charts show estimated parameter and $\mathrm{a}+/-2$ standard error confidence band.

Fig. 2 Probit model estimates, horizons 1-24 months, 1974M1-2017M10. a Spread, estimated coefficients. b Recession dummy, estimated coefficient. c Constant. Charts show estimated parameter and a \pm 2 standard error confidence band 


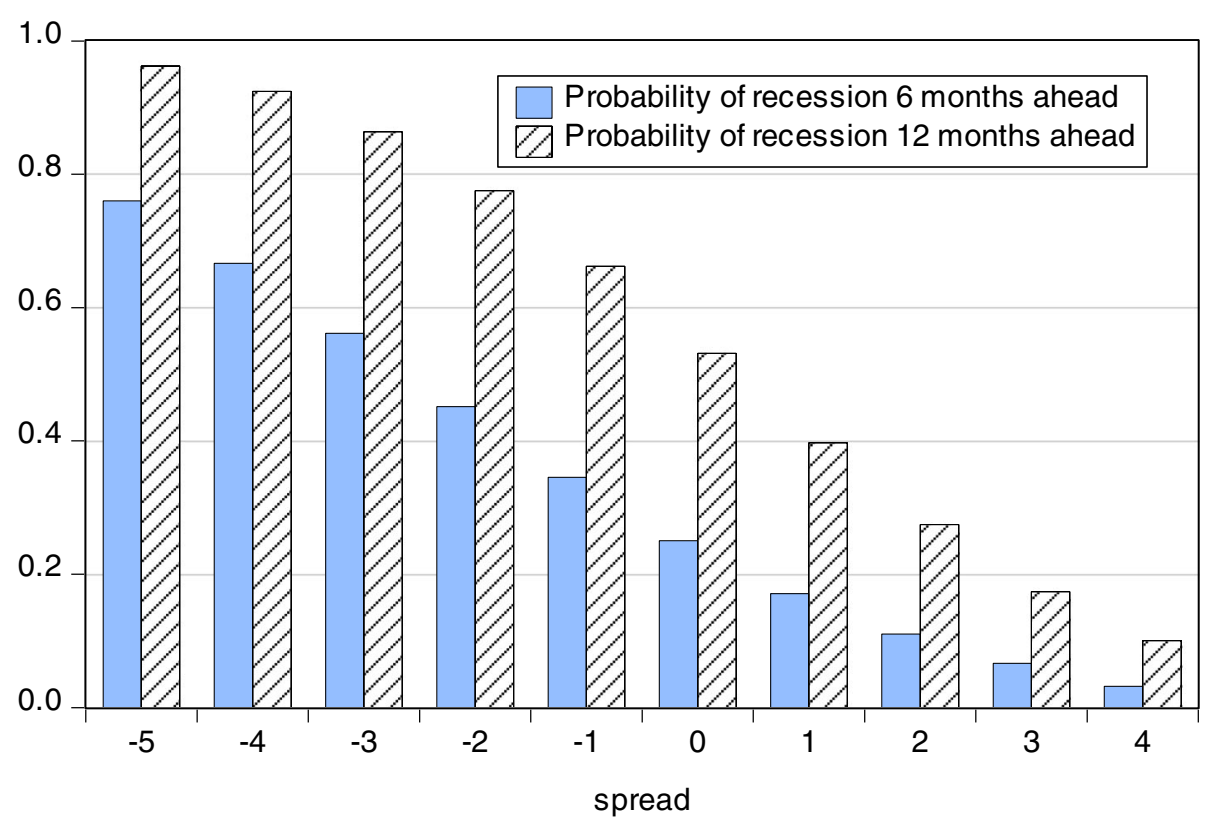

Fig. 3 Probability of a recession 6 and 12 months ahead as a function of spreads, assuming the economy is currently not in recession

\subsection{Fit}

The pseudo $r$-squareds ${ }^{25}$ for each prediction horizon are presented in Fig. 4 (solid line). These are largest at short horizons. However, they decline quite rapidly as the horizon increases, before leveling out at horizons around 6 months. The pseudo $r$-squared rises once the recession dummy becomes significant again (around the 14-month horizon), although it then declines rapidly as the spread becomes insignificant at the 19-month horizon.

Figure 5 shows the predicted recession probabilities from the probit models for $h=6$ and $h=12$. For ease of interpretation, the data are offset so that the chart can be read as the probability of being in recession today, based on data from 6 months previously and 12 months previously. The estimated probabilities tend to rise somewhat in advance of recessions, particularly those for $h=12$. Probabilities are highest during recessions in the first half of the sample period: the model is predicting that the economy will continue in recession. In contrast, probabilities in the post-2007/2008 period are much lower in advance of recessions. The probability from the 6-month ahead model tends to increase sharply once the economy is already in recession, a result which appears to arise due to the lagged recession indicator. ${ }^{26}$

\footnotetext{
${ }^{25}$ Proposed by Estrella (1998), this pseudo $r$-squared is calculated as: 1 $-\left(\frac{L_{u}}{L_{c}}\right)^{-\frac{2}{2} L_{c}}$, where $L_{u}$ is the log likelihood of the estimated model, $L_{c}$ is the likelihood including only a constant as a regressor, and $n$ is the number of observations.

${ }^{26} \mathrm{~A}$ similar pattern is not observed in the predicted probability 12 months ahead since the lagged recession indicator is not statistically significant at this prediction horizon.
}

To summarise the findings of this section, it appears that the slope of the term structure has predictive power for recessions in Switzerland for horizons up to 19 months ahead, which appears a relatively long horizon when compared with results in the literature for small open economies. In terms of fit, the pseudo r-squareds indicate that the fit is best at shorter horizons. The current state of the economy is also significant in this model; however, the sign of the coefficient depends on the forecast horizon. In addition, the relationship is stable over the sample period since 1974.

\subsection{Are all recessions the same?}

One question that arises is whether there is anything special about the recessions which are preceded by marked inversions, compared to the recessions before which the term spread simply narrows. To this end, Fig. 6 shows the Swiss term spread in the 12 months before and after the start of each of the eleven recessions in the sample period. From this figure, it is evident that the level of the spread was considerably lower in advance of the three recessions beginning in 1974, 1981, and 1990, and rises in a more pronounced manner thereafter compared to the remaining recessions. This raises the possibility that the explanatory power of the term spread in Switzerland may be coming from these episodes.

One possibility is that there was some shift in the level and/or volatility of the spread over the course of the sample period. Indeed, a visual examination of Fig. 1 suggests that the level may have increased in the second half of the sample period, causing inversions to be less 


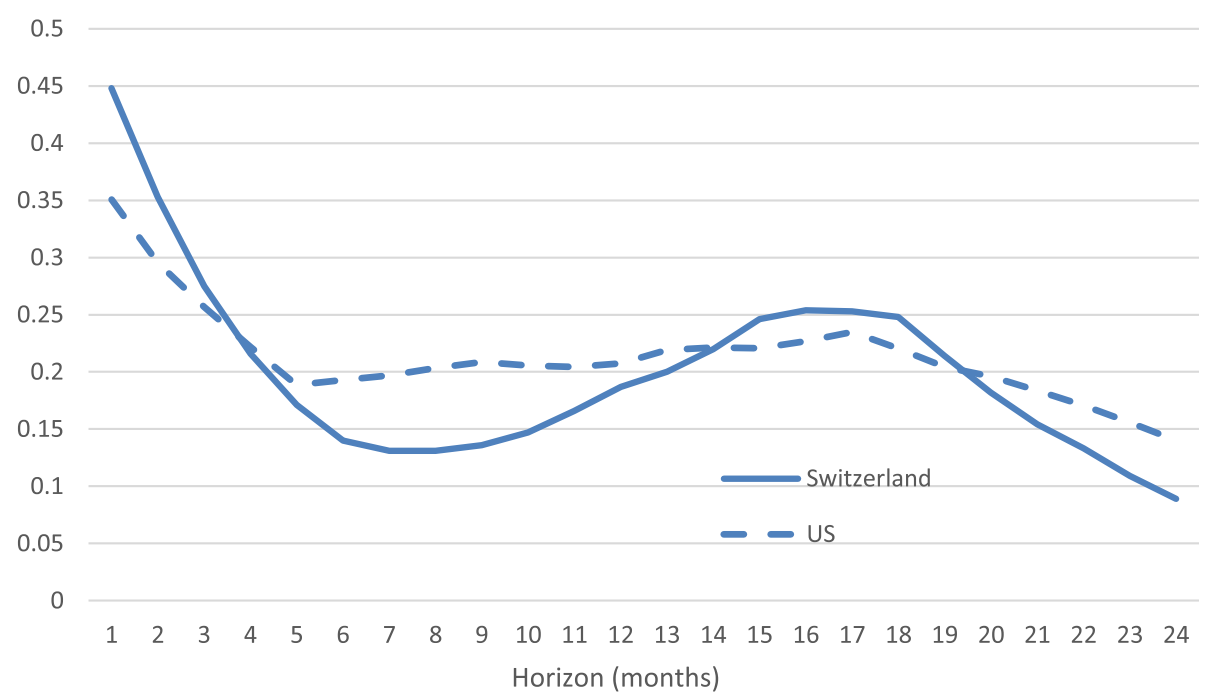

Fig. 4 Pseudo $r$-squareds for $h=1$ to 24 , Switzerland and the US

frequent. To consider this in more detail, I filter the term spread to remove the trend using a band pass filter, to remove the trend. ${ }^{27}$ The remaining "cycle" series is presented in Fig. 7 along with the recession indicator. This filtered series appears to provide a stronger signal in advance of recessions in the latter part of the sample.

When the filtered term spread series is included instead of the unfiltered series as an explanatory variable in the baseline specification, it is significant for horizons of up to 19 months. While these horizons are similar to those obtained using the unfiltered series, the fit improves compared to the unfiltered data. ${ }^{28}$ Specifically, the pseudo $r$-squared of the probit including the filtered regression is larger for all horizons up to 19 months ahead. ${ }^{29}$

Thus, it appears that removing the trend by filtering the data raises the predictive power of the term spread. Nonetheless, since the results for the unfiltered series are strong, the robustness analysis below focusses on this series rather than the filtered one.

\footnotetext{
${ }^{27}$ A Baxter King filter with 36 months lead/lag and a band of 1.5 to 8 years is used. A Hodrick Prescott filter was also considered. While this also generally resulted in an improvement compared to the unfiltered spread, the results from the Baxter King filtered series were stronger and are therefore reported here.

${ }^{28}$ For this comparison, the model using the unfiltered data is reestimated dropping the first and last 36 months of the sample period, to be the same as the sample for the band pass filtered data.

${ }^{29}$ In addition, the out-of-sample fit, measured using the method set out in Section 4.7, also indicates that the probit including the filtered series outperforms the baseline for all horizons up to 18 months ahead.
}

\section{Robustness analysis}

This section carries out a number of robustness checks. In the first instance, I consider alternative measures of the term spread. The analysis so far has been conducted using the spread between the 3-month rate and the 10year government bond yield. I therefore consider the impact that alternative measures of the short rate have on the predictive power of the term spread.

Next, I consider the information content of the term structure compared to that of other possible indicators. Here, the list of alternative indicators is potentially quite broad. However, it is restricted in the first instance to the set of variables that are available on a monthly frequency for the period since 1974. Furthermore, I avoid indicators that are included in the calculation of the recession dummy. This narrows the possible set of indicators considerably.

Since Switzerland is a small open economy, I first consider the role of external developments in predicting recessions, specifically the term spread in other countries. Second, I consider the role of other leading indicators of the Swiss business cycle. Finally, I consider the role of monetary aggregates, which have been shown to have predictive power for economic activity in similar studies for other countries. ${ }^{30}$

I first add each variable separately to the baseline specification, which includes the term spread and the lagged recession indicator. Subsequently, some of the variables are included in combination. Finally, I consider the in-

\footnotetext{
${ }^{30}$ See for instance Albuquerque, Baumann, and Seitz (2015) for a study relating to the US. In terms of smaller economies, see Siklos and Barton (2001) for a study of Canadian data.
} 


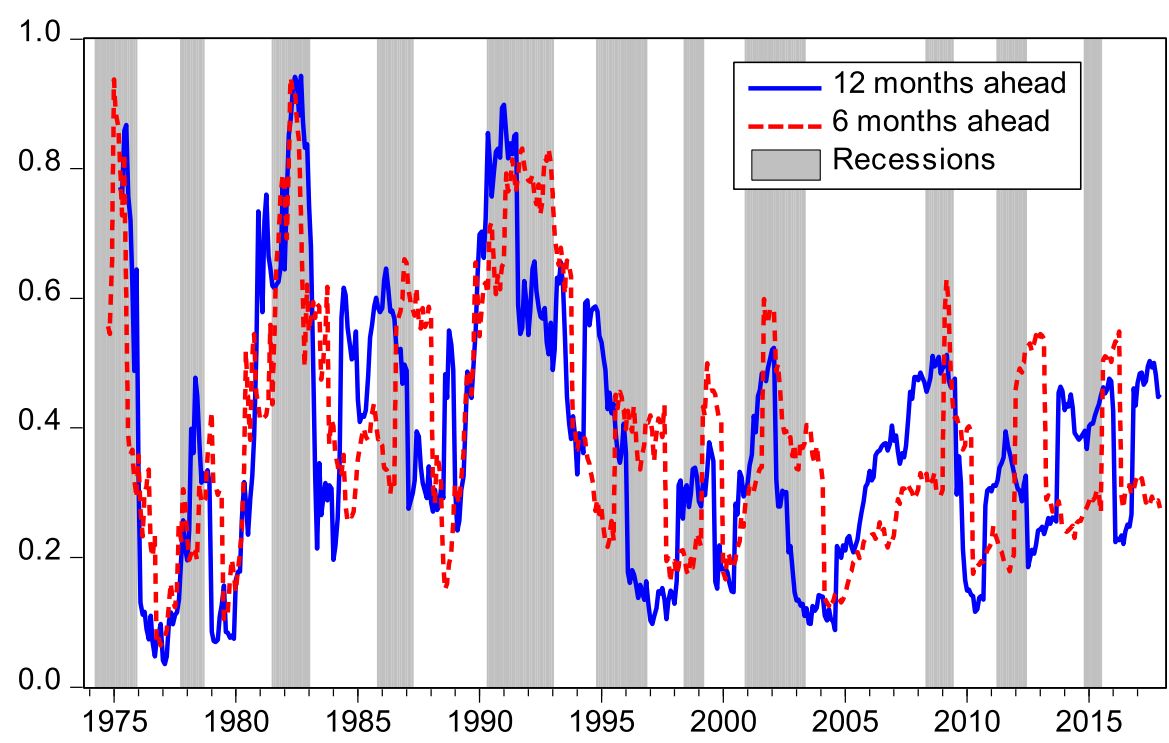

Note: Data in the chart are offset so that the chart can be read as the probability of being in recession today, based on data from 6 months previously and 12 months previously.

Fig. 5 Predicted recession probabilities for $h=6$ and $h=12$, recession indicator. Data in the chart are offset so that the chart can be read as the probability of being in recession today, based on data from 6 months previously and 12 months previously

sample and out-of-sample fit of these augmented models, and compare them to the baseline specification.

\subsection{Alternative measures of the term spread}

So far, the baseline model has been based on a term spread calculated using a 3-month rate. However, as noted in Bauer and Mertens (2018), although the academic literature tends to focus on the spread between a 3-month rate and a 10-year rate, financial commentators often use a 2-year rate instead of a 3-month rate. Therefore, I next consider some alternative measures of the short rate used in calculating the spread.

There are limited interest rate/bond yield series available on a monthly frequency for extended sample periods. Here, I consider three series: 1- and 2-year Swiss Confederation bond yields, which are available since February 1987, and a Swiss Franc 1-year deposit rate, which is available for the longest sample period, from January $1975 .{ }^{31}$ To my knowledge, these are the interest rate series with the longest available sample periods. ${ }^{32}$

These three interest rates, along with the 3-month rate used in the baseline specification, are presented in Fig. 8 .

\footnotetext{
${ }^{31}$ Data are sourced from Datastream.

${ }^{32}$ For instance, monthly Confederation bond yield data in the SNB historical database relates to yields on bonds with a residual maturity of at least 5 years.
}

It is clear from the figure that the three series move very similarly, even though the level of the series differs.

Three new term spreads are obtained by calculating the difference between the 10-year rate and each of these short interest rates in turn, and the same specification is used as in Section 3. The results indicate that when the 1 -year Confederation bond rate is used, the term spread is significant at the $5 \%$ level up to 22 months ahead. For the 2-year Confederation bond yield, the predictive horizon is 24 months. Since these series are only available from February 1987, I re-estimate the baseline model which uses the 3-month rate to calculate the term spread, over the same sample period. Using this measure, the parameter on the spread has predictive power up to 23 months ahead, approximately the same horizon as the alternative spreads.

Finally, in the case of the spread calculated using the 1 -year deposit rate, the parameter is significant in predicting recessions up to 18 months ahead. This spread is available since January 1975 . The baseline model estimated over this sample period indicates that the spread has predictive power for recessions up to 19 months ahead.

Overall, the results using the baseline model with the spread calculated using the 3-month rate appear very similar to those using all alternative measures of the short interest rate. Thus, it appears that the results are largely robust to the choice of short interest rate used to calculate the spread. 


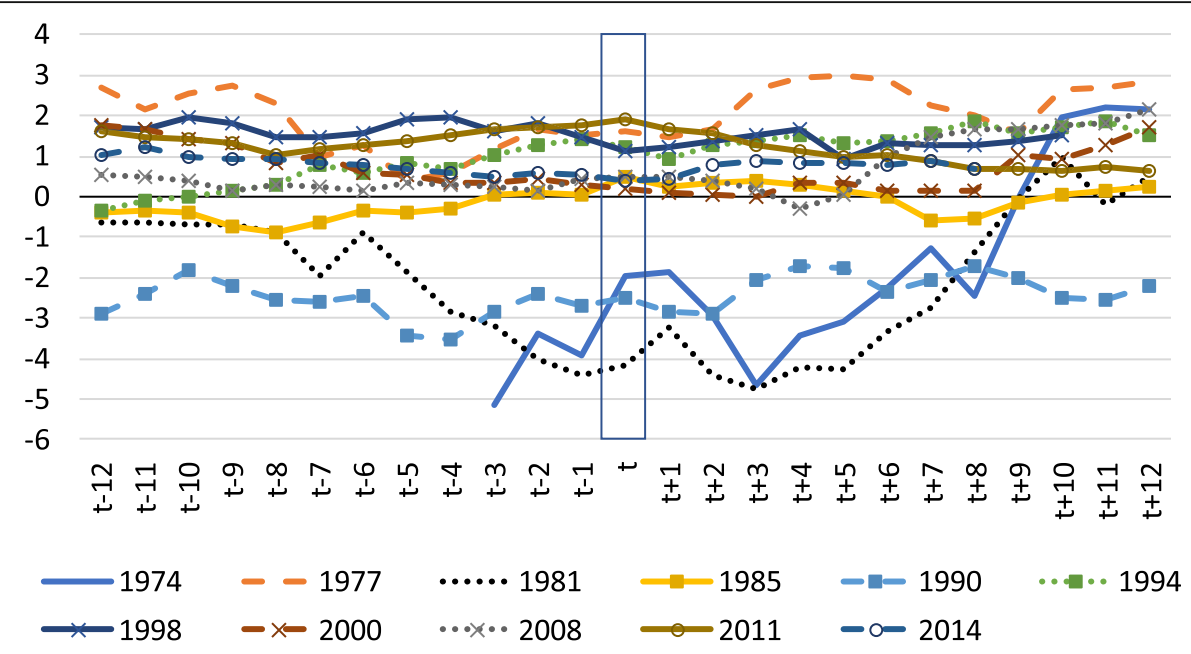

Note: $t$ indicates the first month of a recession.

Fig. 6 Term spread 12 months before and after the onset of a recession. $t$ indicates the first month of a recession

\subsection{Foreign spreads}

Some studies, for instance Bernard and Gerlach (1996), find that foreign term spreads are also significant predictors of recessions in some countries. As a small open economy, this may be particularly relevant in Switzerland. However, it may also be the case that the Swiss monetary policy-and therefore the Swiss term structure-responds to external as well as domestic shocks, and therefore captures the information in foreign spreads.

Here, I consider the explanatory power of the German and the US term spreads. The German spread is chosen because of the important economic and financial links between Germany and Switzerland. The US spread may capture a "global" monetary policy stance. In both instances, I use the spread between 10-year and 3-month rates, to be similar to the specification of the baseline Swiss spread. The spreads are included separately in the baseline specification which includes the term spread and the lagged recession indicator. However, in both instances, the foreign spread is insignificant at the $5 \%$ level at any horizon from 1 to 24 months when included alongside the Swiss spread, and the results are therefore not shown here in the interests of brevity. ${ }^{33}$ Thus it appears that the Swiss term spread captures external as well as domestic conditions.

\footnotetext{
${ }^{33}$ For instance, at the baseline 6-month horizon used in Section 3.1, the p-value on the German spread is 0.95 , while the p-value on the US spread is 0.80 .
}

\subsection{Leading indicators of the business $\mathrm{cycle}^{34}$}

Next, I consider the role of other leading indicators of the business cycle. ${ }^{35}$ There are few such indicators available on a monthly basis for the full sample period from 1974 . Here, I use the KOF business course indicator ${ }^{36}$ and the OECD business confidence indicator (BCI). ${ }^{37}$ As is evident from Fig. 9, these latter two series move similarly, although there are also several periods when they diverge. Nonetheless, both series tend to decline in advance of recessions and rise towards, or immediately after, their end.

One reason for this close co-movement may be that both series are compiled from business tendency survey responses collected by KOF. In addition, three of the six series which are used in the composition of the OECD's composite leading indicator (CLI) series, on which the recession dummy is based, relate to these responses. ${ }^{38}$ What degree of overlap is there? It appears that two of the three survey responses used to calculate the $\mathrm{BCI}$ are also used in the CLI. ${ }^{39}$ Thus there is some overlap between the series.

\footnotetext{
${ }^{34}$ With thanks to participants at a University of Neuchâtel research seminar for suggestions regarding leading indicators.

${ }^{35}$ The growth in the stock market was also suggested as a potential indicator. However, it proves to be insignificant at all but the shortest horizons (one to two months). Moreover, share prices are a constituent series of the recession indicator. Therefore, it is not reported here.

${ }^{36}$ Accessed via Datastream.

${ }^{37}$ Another candidate series which is available for the full sample is the OECD's CLI. However, this is used directly in the computation of the recession dummy, and so is not considered here.

${ }^{38}$ See footnote 10 above for the six series used to calculate the CLI.

${ }^{39}$ The $\mathrm{BCI}$ as the simple average of balance series from KOF survey questions on order receipts, production, order books and stocks of finished goods. See: http://www.oecd.org/sdd/leading-indicators/ glossaryforoecdcompositeleadingindicators.htm\#BUSINESS CONFIDENCE_INDICATOR
} 


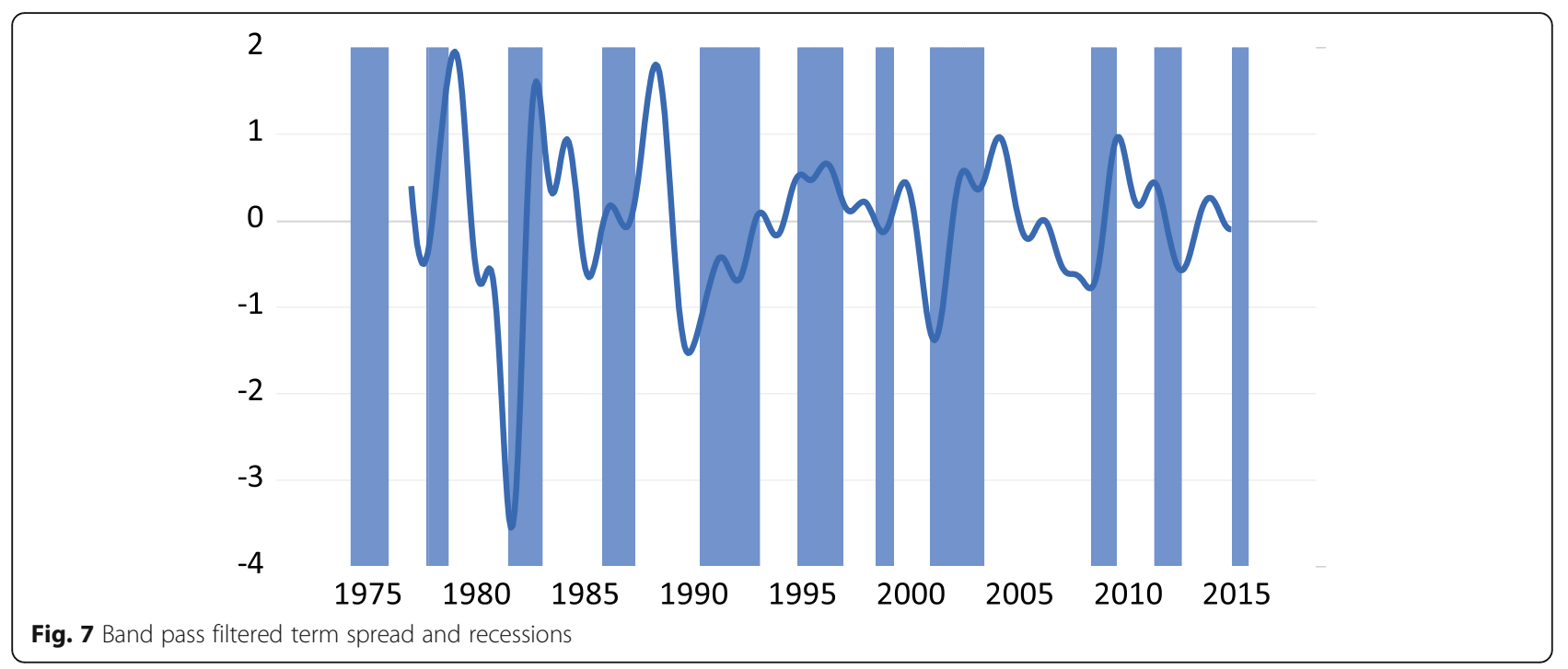

However, the BCI uses no smoothing of the time series (only seasonal adjustment), while the data are smoothed for the CLI. In contrast, the KOF business course indicator is based on responses to three questions which do not appear to overlap with the series used in the CLI. ${ }^{40}$ Although this implies that there is no direct overlap between the series used to calculate the recession indicator and this series, the survey questions used in the recession indicator are also from the KOF, and thus the respondents overlap.

These series are individually included in the probit models for horizons $h=1$ to 24 . Table 2 presents the results. In the interests of brevity, the table summarises the horizons, in months, for which the estimated coefficients of the explanatory variables are significant at the 5\% level. Column 1 presents the results for the OECD BCI. The parameter on the BCI is insignificant at all horizons with the exception of $h=10$ and 11 . Turning to the results when the KOF business course indicator (column 2), the coefficient on the KOF indicator is significant for horizons of 2 to 15 months. The coefficient on the spread is significant at horizons similar to the baseline specification (18 months compared with 19 months in the baseline). Not shown, the magnitude of the coefficient is also similar to, if slightly smaller than, the baseline specification. The coefficient on the recession dummy follows the same pattern as before, taking positive and significant values at short horizons $(h<9)$ and negative and significant values at longer horizons $(h>15)$.

\footnotetext{
${ }^{40}$ Specifically, order income compared to year before, production compared to year before and an assessment of backlog of orders.
}

\subsection{Monetary aggregates ${ }^{41}$}

The final set of indicators considered here are the annual growth rates in monetary aggregates, M1, M2, and M3. These data are collected primarily from the SNB website. Monthly historical data are spliced with the currently updated series. For M2 and M3, data are only available on a semi-annual frequency prior to June 1975. For M3, monthly data for this period are sourced from the Federal Reserve Bank of St Louis' FRED database. ${ }^{42}$ For M2, the data are interpolated using the Chow-Lin methodology. This is a regression-based interpolation technique that uses higher-frequency indicator series to interpolate the lower-frequency series. ${ }^{43}$ I use the annual growth rates of M1 and M3 to interpolate M2 growth.

These three monetary aggregates are added separately to the baseline specification. The results indicate that M1 and M2 growth are the most useful monetary aggregates considered. From column 3 of Table 2, the coefficient on M1 is significant at shorter horizons of up to 1 year, and longer horizons beyond 21 months. By comparison, the coefficient on M2 is significant only at short horizons of up to 7 months (column 4), while M3 is not significant at any horizon and is therefore not reported in Table 2. Again, we find that the Swiss term spread continues to be significant for horizons similar to in the baseline model despite the addition of these new variables to the model. The significance of the recession dummy also follows a similar pattern to the baseline,

\footnotetext{
${ }^{41}$ I thank participants at the Swiss Society of Economics and Statistics annual conference 2018 for suggesting this analysis.

${ }^{42}$ The FRED database notes that these data are in turn sourced from the OECD.

${ }^{43}$ For a discussion of the Chow-Lin methodology with an application to Swiss real GDP data, see Stuart (2018).
} 


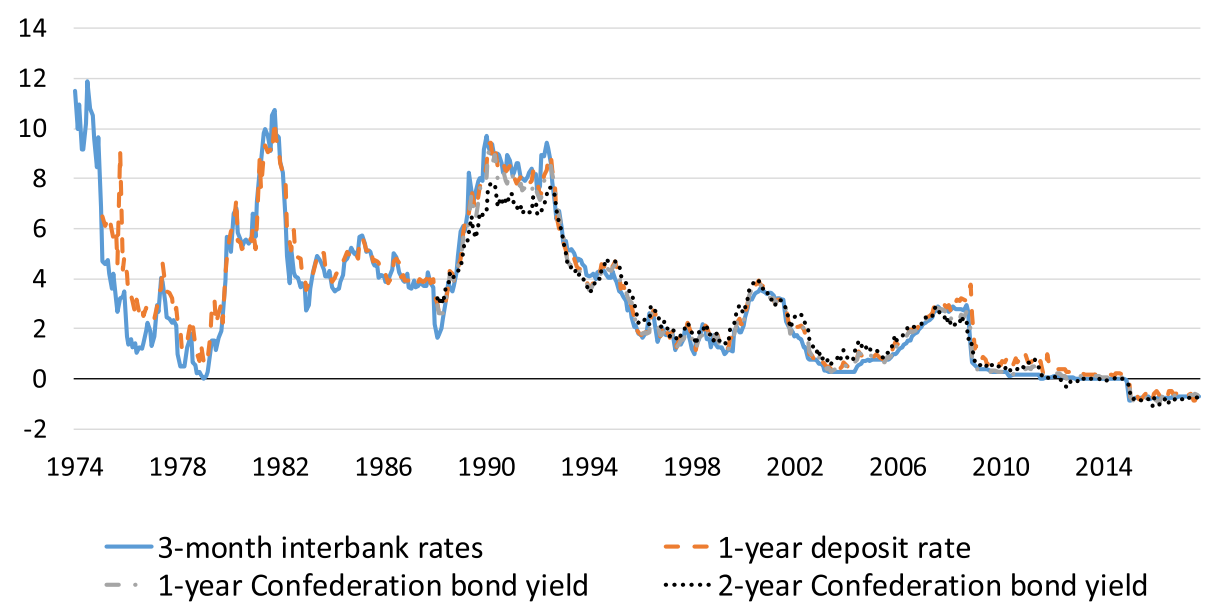

Fig. 8 3-month interbank rate and alternative measures of short interest rates

although the change in sign of the coefficient occurs at somewhat shorter horizons when the monetary aggregates are included.

Overall, the results above suggest that the KOF indicator, M1 and M2 growth are perhaps the most useful additional indicators for predicting recessions in addition to the term spread in the sample period studied. The question arises whether combinations of these variables may improve the model fit further. I turn to this next.

\subsection{Combined models}

The final two columns of Table 1 provide results for models including more than one of the variables in the model. Specifically, column 5 shows results when both the KOF indicator and M1 growth are included, while column 6 shows results when the KOF indicator and M2 growth are included. (Other combinations are excluded as the results indicate that coefficients are rarely, if ever, significant.) Column 5 indicates that the spread continues to be significant at horizons up to 18 months when both the KOF indicator (significant at horizons of 5 to 15 months), and M1 growth (significant at horizons up to 11 months, and beyond 22 months) are included. This is also the case in column 6 (again the spread is significant to horizons up to 18 months). From this column, the KOF indicator is significant for horizons of 2 to 16 months ahead, and M2 growth continues to only be significant at shorter horizons ( 1 to 9 months).

Although these indicators are statistically significant in the probit models, they may add little to the overall fit. I next consider the in-sample and out-of-sample fit of these augmented models, and compare them with the baseline specification which includes just the term spread and the lagged recession indicator.

\subsection{In-sample fit}

Since a pseudo $r$-squared will automatically increase when a variable is added, I use the Akaike information criterion (AIC) and the Bayesian information criterion (BIC) to better understand the in-sample fit of the models in Table 2. ${ }^{44}$ Figure 10 shows the models with the lowest AIC and BIC at each prediction horizon (read off left-hand axis). The results using the two information criteria are similar. At very short prediction horizons (1-2 months), and very long horizons (greater than 18 months), adding M1 growth to the baseline model generally leads to the best fit according to these criteria. For prediction horizons of 2-3 months to 13-14 months, the model including the KOF indicator and M1 growth in the baseline specification is the best fitting, while for longer prediction horizons of up to 17-18 months, the model adding the KOF indicator to the baseline provides the best fit.

Overall, two conclusions can be drawn from these results. First, the KOF indicator and M1 growth contain information useful for predicting recessions that is not included in the term spread. Second and relatedly, M1 growth appears to be the most useful of the monetary aggregates for predicting recessions in-sample.

\subsection{Out-of-sample cross validation}

So far, I have considered only the in-sample fit of the models. Testing the out-of-sample fit raises a number of issues. Out-of-sample tests generally require that the model is estimated up to a certain date, and the out-of-

\footnotetext{
${ }^{44}$ This Section and Section 4.7 focus on variables and combinations thereof which proved significant in the preceding sections; specifically the KOF indicator, M1 and M2 growth. The AIC is calculated as: $-2 L+k * 2$, and the BIC is calculated as: $-2 L+k * \log T$, where $L$ is the $\log$ likelihood of the model, $k$ is the number of estimated parameters and $T$ is the number of observations.
} 


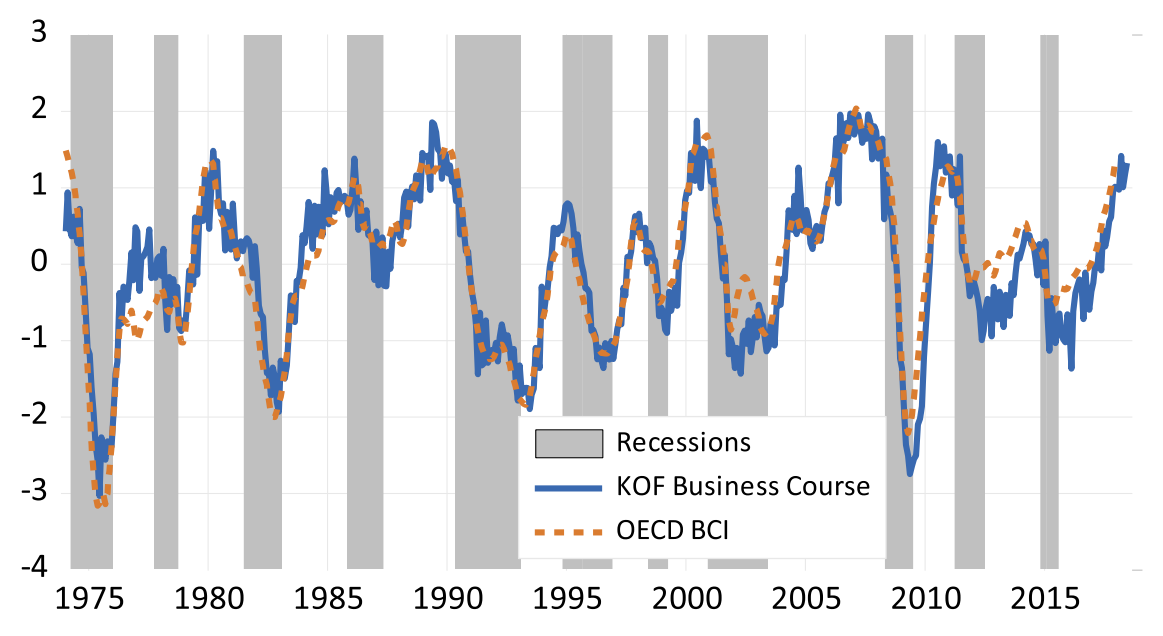

Note: Indicators are normalised to have mean zero and a standard deviation of one for comparability.

Fig. 9 Leading indicators and recessions. Indicators are normalised to have mean zero and a standard deviation of one for comparability

sample forecast for the remainder of the sample is evaluated against the observed data. Choosing this cut-off is arbitrary. Moreover, since the focus of this paper is on the relationship between the term spread and recessions over a sample of more than 40 years, we are interested in the predictive power throughout the sample period, not just in the most recent data.

I therefore use the leave-one-out cross validation method to test the out-of-sample properties of the various estimated models. The leave-one-out method is a special case of the leave-k-out cross validation methods (Bruce and Martin (1989)). This is a widely used approach which estimates the model using multiple subsets of the sample for validation. In a dataset with $n$ observations, the model is run on a subsample of $(n-1)$ observations, and then a fitted value for the omitted observation is estimated. The difference between the fitted value and the observed value of the variable-the error-is calculated and then squared.

This process is repeated so as to exclude every observation once. ${ }^{45}$ The squared errors are then averaged across all test cases to obtain a mean square error (MSE) for the model. The MSE can then be compared across models, with the one with the lowest MSE being considered the best fit.

Figure 10 presents the model with the lowest MSE at each horizon from 1 to 24 months. The MSE is read off the right-hand axis in the figure. Unsurprisingly, the

\footnotetext{
${ }^{45}$ This method creates two "groups" of observations either side of the one being left out. As per Teh et al., (2010), the model is run so that there are never less than 25 observations in a group.
}

MSEs are lowest at the 1-month horizon. However, the MSEs for horizons from approximately 7 months to 24 months are roughly similar, suggesting that the predictive power of the model does not decline much after the 6-month prediction horizon.

Except at very short and very long horizons, models including the KOF indicator and a monetary aggregate perform best: for horizons of 3 to 16 months, models including the KOF indicator in combination with either M1 or M2 growth have the lowest MSE. At very short horizons, the best performing model includes M1 growth alone ( $h=1$ to 2 ). Finally, the model including just the spread performs particularly well at horizons in excess of 16 months.

Overall, therefore, it seems that additional variables can improve both the in- and out-of-sample fit of the models. As such, it appears that the KOF indicator, and monetary aggregates (M1 and M2 growth in particular) contain information not already embedded in the term spread, which give additional predictive power to the model. Nonetheless, the term spread continues to have predictive power for recessions at forecast horizons of at least 1.5 years ahead.

\section{Switzerland and the US}

While a comprehensive international comparison is beyond the scope of this paper, this section makes some comparisons between the Swiss data and results and those from the US. The US is chosen here since it is the focus of the majority of the literature. Nonetheless, the US is a large, relatively closed economy, while the Swiss economy is small and open. As such, it is to be anticipated that the relationship may be stronger in the US than in Switzerland. 
Table 2 Dynamic probit model results, including additional variables, horizons 1-24 months, 1974M1-2017M4

\begin{tabular}{|c|c|c|c|c|c|c|}
\hline & \multicolumn{6}{|c|}{ Horizons at which variables are significant at the $5 \%$ level (months) } \\
\hline & (1) & (2) & (3) & (4) & (5) & (6) \\
\hline Spread & $1-17$ & $1-18$ & $1-18$ & $1-24$ & $1-18$ & $1-18$ \\
\hline Recession (third lag) & $<8,>14$ & $<9,>15$ & $<4,>10$ & $<7,>11$ & $<6,16-23$ & $<8,>15$ \\
\hline $\mathrm{BCl}$ & $10-11$ & & & & & \\
\hline KOF & & $2-15$ & & & $5-15$ & $2-16$ \\
\hline M1 & & & $1-12,22-24$ & & $1-11,22-24$ & \\
\hline M2 & & & & $1-7$ & & $1-9$ \\
\hline
\end{tabular}

The results for the constants are suppressed in the interests of brevity. KOF indicator is normalized to have mean zero and standard deviation one

\subsection{Comparison of recession forecasting, Switzerland and} the US

Figure 11 presents the equivalent data for the US to that used in the analysis for Switzerland: the NBER recession dummy and the spread between the 3-month and 10year Treasury rates. ${ }^{46}$ Compared to Fig. 1, which contains the Swiss term spread and recessions, the pattern of term spread declines and inversions in advance of recessions is clearly more pronounced in the US. This visual inspection suggests that although the Swiss term spread contains information that helps predict recessions, it may not be as strong an indicator as in the US.

Nonetheless, a more formal analysis is required to confirm this. The literature estimates a wide range of specifications, for instance, including the short rate in addition to the spread (Wright (2006)), omitting the current value of the recession indicator (Estrella and Hardouvelis (1991)) or including other financial variables (Estrella and Mishkin (1998)). However, for comparative purposes, here I use the same baseline specification as is used for the Swiss data. The estimated model therefore includes the term spread and the third lag of the recession indicator as explanatory variables.

Results from this exercise indicate that the term spread is a significant predictor of the recessions in the US for periods in excess of 2 years. The in-sample fit, as measured by the pseudo $r$-squared is presented in Fig. 4 (dashed line). The in-sample fit of the model for Switzerland is better at horizons of 1-4 months and 1419 months. In contrast, the out-of-sample fit, measured using the LOO method, indicates that the US model fits better at every horizon. Indeed, the average MSE in the US model across all horizons is less than half that of the Swiss model.

Overall, these results suggest that the relationship between the term spread and recessions is stronger in the US than in Switzerland, particularly in relation to out-

\footnotetext{
${ }^{46}$ The spread is calculated as: 10 -Year Treasury Constant Maturity Rate, Percent, Monthly, Not Seasonally Adjusted minus 3-month Treasury Bill: Secondary Market Rate. A constant maturity 3-month rate is not available prior to 1982. All data are sourced from the Fred database.
}

of-sample forecasting. This result is unsurprising in light of the earlier discussion of the difficulties of using the term structure in small open economies, primarily, the importance of managing the exchange rate in monetary policy setting, and the concurrent role that foreign-rather than domestic-macroeconomic developments play in interest rate setting.

\subsection{Length of recessions, Switzerland and the US}

A comparison of Figs. 1 and 11 suggest that Swiss recessions are longer, and in fact, on average Swiss recessions extend 19 months on average, whereas US recessions extend just 12 months on average. One potential issue that arises therefore is that the longer recessions experienced in Switzerland are driving the predictive result.

To examine this more formally, I next limit the length of each recession to be at maximum 12 months long, the same duration as the average US recession. I then re-estimate the baseline specification above, with missing values included in the recession indicator for months in which a recession in excess of 12 months was recorded. The results indicate that the spread parameter continues to be significant for forecasting recessions up to 15 months ahead.

Thus, it appears that although Swiss recessions are longer than those in the US, this is not driving the result that the term spread has predictive power for recessions in Switzerland.

\section{Conclusions}

There is a large literature that has established the slope of the term structure as a reliable indicator of recessions in the US. A smaller literature exists testing this relationship for other countries. As such, there is limited evidence of the predictive power of the term structure of interest rates for recessions in small open economies, and no similar study has yet been carried out for Switzerland.

Being small and highly open, Switzerland has experienced a number of external shocks since the Swiss Franc was floated in 1974. These include the oil crisis, the global slowdown in the 1980 s, the reunification of 


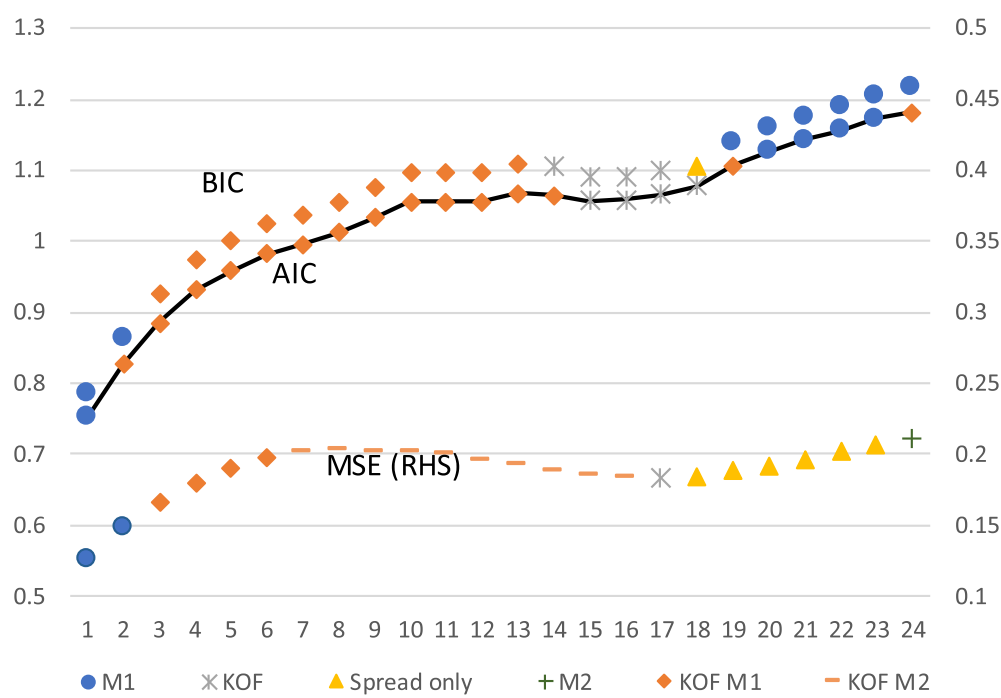

Note: MSE calculated using LOO method.

Fig. 10 Models generating lowest AIC, BIC and MSE (RHS) at each horizon

Germany, and the exchange rate crisis in the EMS in the 1992-1993, and the dotcom and global financial crises in the 2000s. Thus, it is an interesting case to study the predictive power of the term structure in a small open economy setting.

In this paper, I used probit models to estimate the usefulness of the term structure for forecasting recessions in Switzerland over the period 1974-2017. There are four main findings. First, the model provides substantial evidence that the slope of the term structure contains information that helps forecast recessions for horizons out to 19 months. The result is largely unchanged when alternative specifications of the term spread are used. This result compares favorably with those in studies of other small open economies. Comparing the results for
Switzerland with a similar specification for the US (a large, relatively closed economy) indicates that the insample fit of the models is similar, although the US model has a better out-of-sample fit.

Second, whether the economy is currently in recession or not also contains useful information. For short forecast horizons, the results indicate that the economy is expected to stay in its current state; for longer forecast horizons, the results show that the economy is likely to change state.

Third, testing for structural breaks at several different plausible points indicates that the relationships between these variables are stable over the entire 43-year sample.

Fourth, robustness tests in which a number of plausible alternative predictors of recessions are included in

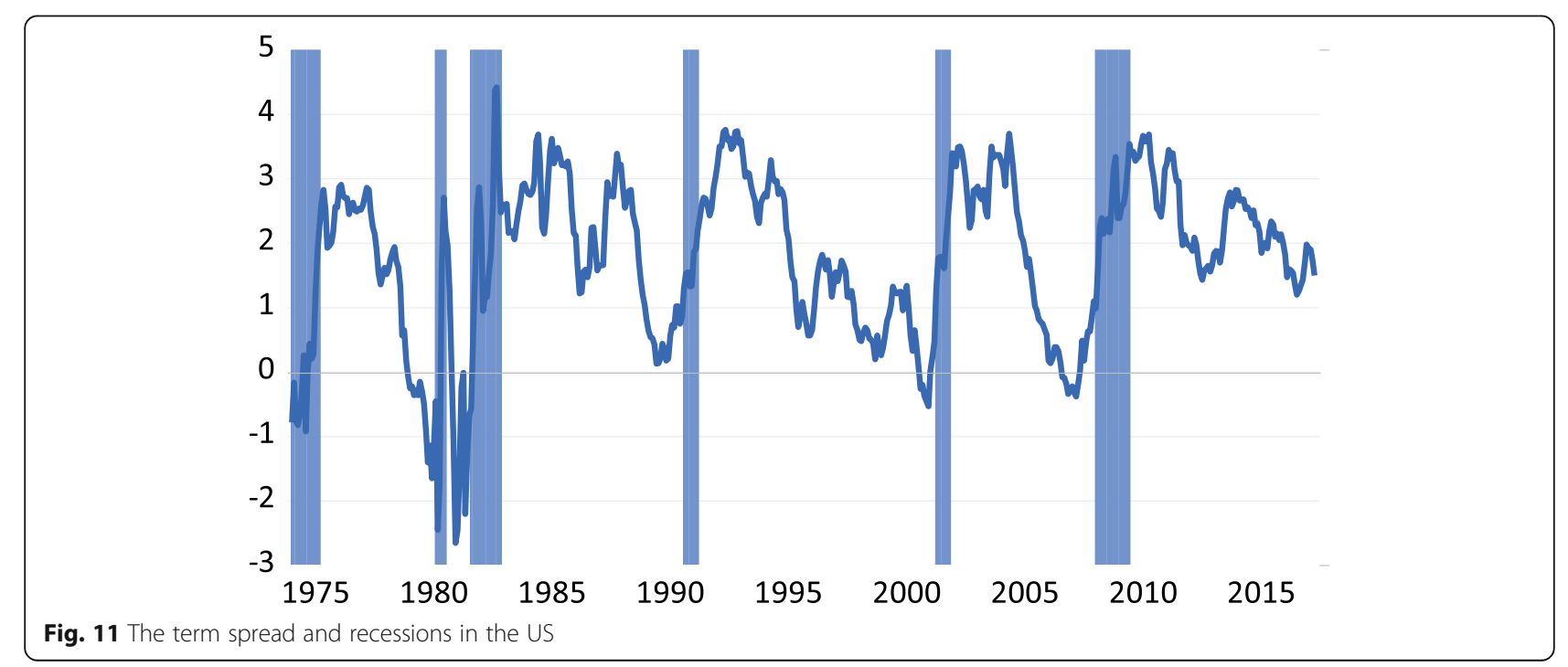


the baseline regression suggest that the KOF business course indicator and M1 growth, in particular, contain information that is beneficial for forecasting recessions and is not included in the slope of the term structure. Both variables are significant when added separately and together in the baseline specification, while the term spread continues to be significant at similar prediction horizons to the baseline. Moreover, including these variables can improve the in-sample fit of the model. In outof-sample testing, the KOF indicator, in combination with M1 or M2 growth, improves the overall fit of the model at prediction horizons of 4 to 18 months.

\section{Abbreviations \\ AIC: Akaike information criterion; $\mathrm{BCl}$ : Business confidence indicator; BIC: Bayesian information criterion; CLI: Composite leading indicator; EMS: European Monetary System; GDP: Gross domestic product; KOF: KOF Swiss Economic Institute; MSE: Mean square error; OECD: Organisation for Economic Co-operation and Development; SNB: Swiss National Bank; US: United States of America}

\section{Acknowledgements}

I am very much indebted to an anonymous referee for helpful comments that strengthened the analysis; and to Klaus Abberger for several very helpful clarifications on the KOF business tendency survey data. I would like to thank the editor, Daniel Kaufmann, Ronald Indergand, Stefan Gerlach, and participants at the Swiss Society of Economics and Statistics annual conference 2018 and at seminars at University of Neuchâtel and at the State Secretariat for Economic Affairs (SECO), Bern, for helpful comments, and Conor Parle for research assistance.

\section{Authors' contributions}

The author read and approved the final manuscript.

\section{Authors' information}

The views expressed in this paper are solely my own and do not represent those of the Central Bank of Ireland or the Eurosystem.

\section{Funding}

This research was not supported by any external funding

\section{Availability of data and materials}

Ten-year and 3-month interest rate data for Switzerland, the US and Germany and the recession indicators for Switzerland and the US were obtained from the Federal Reserve Bank of St Louis' FRED database: https://fred. stlouisfed.org/. GDP data were obtained from SECO: https://www.seco.admin. ch/seco/en/home/wirtschaftslage - wirtschaftspolitik/Wirtschaftslage/bipquartalsschaetzungen-/daten.html. The OECD's BCl and monthly M3 data prior to June 1975 were obtained from the OECD database: https://stats. oecd.org/. All remaining monetary aggregate data were obtained from the SNB's website: https://data.snb.ch/en. The KOF Business Course indicator, 1and 2-year Confederation bond data, and the 1-year deposit rate were obtained from Datastream.

\section{Competing interests}

The author declares that she has no competing interests.

Received: 19 September 2018 Accepted: 28 August 2019

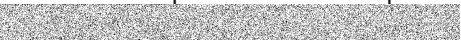

\section{References}

Adrian, T., A. Estrella and H. S. Shin, (2018), Risk-taking channel of monetary policy, CEPR Discussion Paper Series, DP12677.

Albuquerque, Bruno, Ursel Baumann and Franz Seitz, (2015), The information content of money and credit for US activity, ECB Working Paper No. 1803, June.

Baltensperger, Ernst and Peter Kugler, (2016), Swiss Monetary History since the early 19th Century, unpublished manuscript, June.
Bauer, Michael D. and Thomas M. Mertens, (2018), Economic forecasts and the yield curve, Federal Reserve Bank of San Francisco, Economic Letter, 2017-07, March.

Bernard, Henri and Stefan Gerlach, (1996), Does the term structure predict recessions? The international evidence, BIS Working Paper No. 37.

Bernholz, Peter, (2007), From 1945 to 1982: the transition from inward exchange controls to money supply management under floating exchange rates, in Swiss National Bank, 1907-2007, Neue Zürcher Zeitung Publishing, Zurich.

Bruce, A. G., \& Martin, R. D. (1989). Leave-k-out diagnostics for time series. Journal of the Royal Statistical Society, 51(3), 363-342.

Dueker, Michael J., (1997), Strengthening the case for the yield curve as a predictor of United States recessions, Federal Reserve Bank of St Louis Review, 41-51, March/April.

Estrella, A. (1998). A new measure of fit for equations with dichotomous dependent variables. Journal of Business and Economic Statistics, 16(2), 198205.

Estrella, A., \& Hardouvelis, G. A. (1991). The term structure as a predictor of real economic activity. Journal of Finance, 46(2), 555-576.

Estrella, A. and F. Mishkin, (1995), The term structure of interest rates and its role in monetary policy for the European Central Bank, NBER working paper, 5279, September

Estrella, A., \& Mishkin, F. (1998). Predicting U.S. recessions: financial variables as leading indicators. The Review of Economics and Statistics, 80(1), 45-61.

Forbes, (2016), Absolutely fascinating-Apple's EU tax bill explains Ireland's 26\% GDP Rise, article by Tim Worstall, September 8, 2016. https://www.forbes. com/sites/timworstall/2016/09/08/absolutely-fascinating-apples-eu-tax-billexplains-irelands-26-gdp-rise/\#787d437e1a70

Gerlach, S., \& Jordan, T. (2012). Tactics and strategy in monetary policy: Benjamin Friedman's thinking and the Swiss National Bank. International Journal of Central Banking, 8(S1), 23-56.

Gerlach, S., \& Stuart, R. (2018). The slope of the term structure and recessions: the pre-fed evidence (pp. 1857-1913) CEPR Discussion Paper No. 13013.

Gerlach-Kristen, P. (2007). Three aspects of the Swiss term structure: an empirical survey. Financial Markets and Portfolio Management, 21(2), 221-240.

Harvey, C. R. (1989). Forecasts of economic growth from the bond and stock markets. Financial Analysts Journal, 38-45 September-October.

Jorion, P., \& Mishkin, F. (1991). A multicountry comparison of term structure forecasts at long horizons. Journal of Financial Economics, 29, 59-80.

Kauppi, H., \& Saikkonen, P. (2008). Predicting US recessions with dynamic binary response models. Review of Economics and Statistics, 90(4), 777-791.

Kleinewefers Lehner, Anne, (2007), Economic Trends', in Swiss National Bank, 1907-2007, Neue Zürcher Zeitung Publishing, Zurich.

Mishkin, F. S. (1991). A multi-country study of the information in the shorter maturity term structure about future inflation. Journal of International Money and Finance, 10, 2-22.

Moneta, F. (2005). Does the yield spread predict recessions in the euro area? International Finance, 8(2), 263-301.

Nelson, E. (2007). Ireland and Switzerland: The jagged edges of the Great Inflation. European Economic Review, 52, 700-732.

Rich, Georg, (2003), Swiss Monetary Targeting 1974-1996: the role of internal policy analysis, ECB Working Paper Series, 236, June.

Siklos, P. L., \& Barton, A. G. (2001). Monetary aggregates as indicators of economic activity in Canada: empirical evidence. The Canadian Journal of Economics / Revue canadienne d'Economique, 34(1), 1-17.

Stuart, R. (2018). A quarterly Phillips Curve for Switzerland using interpolated data, 1963-2016. Economic Modelling, 70, 78-86.

Teh, S. Y., Othman, A. R., \& Khoo, M. B. C. (2010). Dichotomous logistic regression with leave-one-out validation. International Journal of Mathematical and Computational Sciences, 4(2), 296-305.

Wright, Jonathon $\mathrm{H}_{\text {., }}$ (2006), The yield curve and predicting recessions, Federal Reserve Board, Finance and Economics Discussion Paper 2006-07.

\section{Publisher's Note}

Springer Nature remains neutral with regard to jurisdictional claims in published maps and institutional affiliations. 